\title{
INFORME SOBRE A FONTE DE TRONCOSO E A SÚA SITUACIÓN DE EMERXENCIA
}

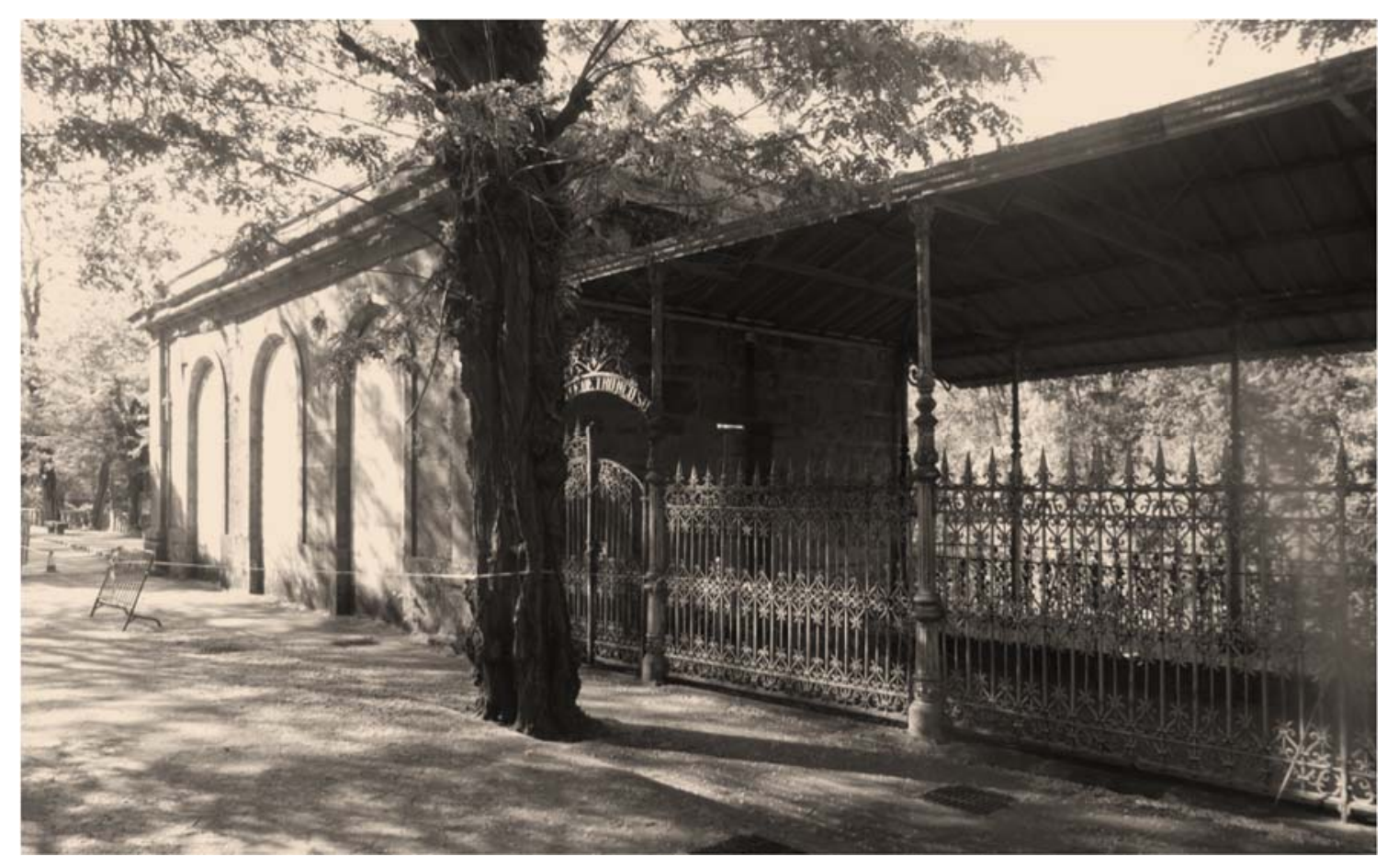

DOI: $107075 /$ isftse.2020

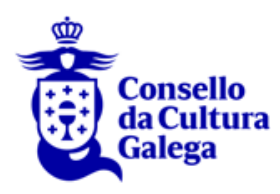


Con data de 26 de setembro de 2019 ten entrada no rexistro do Consello da Cultura Galega a solicitude de informe presentada por Alberte Reboreda Carreira (DNI 76898 585-V), con relación ao estado de conservación do elemento patrimonial catalogado coñecido como Fonte de Troncoso, Augas de Abaixo ou Saidoiro (coord. UTM 543271, 4675038), que sinala o estado de avanzada deterioración deste ben.

\section{Antedecentes}

No ano 2015 o Consello da Cultura Galega (en diante CCG), a petición da PLATAFORMA DE DEFENSA DOS XARDÍNS DO BALNEARIO DE MONDARIZ, que solicitaba a valoración do Convenio urbanístico de planeamento para modificación do proxecto de ordenación do medio rural no ámbito do espazo coñecido como Xardíns do Gran Hotel, establecido entre o Concello de Mondariz e a Empresa SODESMON (con data do 17.10.2013), xa que se consideraba que vulneraba aspectos fundamentais dos valores identitarios e culturais do territorio onde se sitúa o antigo Balneario de Mondariz, emitiu o INFORME SOBRE A UNIDADE DO CONXUNTO DO HOTEL-BALNEARIO DE MONDARIZ, que está dispoñible na páxina web do mesmo CCG.

Neste informe analizábase brevemente a peza que nos ocupa no presente documento. Infórmabase que a Fonte de Troncoso formaba parte do proxecto levado a cabo nunha primeira fase, conformado por unha unidade entre o xardín, o bosque e unha serie de edificacións paralelas ao río Tea, que remataban nun pequeno conxunto formado pola Fonte de Troncoso e o muíño, e que correspondían á fase anterior a 1907. O edificio alberga a Fonte, que foi arquitecturizada por Antonio Palacios e que incluía a recuperación de elementos da antiga fonte da Gándara. Naquel informe facíase fincapé na relación do elemento coa unidade cultural, arquitectónica e paisaxística do meta-proxecto de Hotel-Balneario. E para a totalidade do conxunto propoñíase a súa incorporación ao rexistro de Bens de Interese Cultural de Galicia (BIC), de xeito que se lle outorgase a máxima protección contemplada pola Lei do patrimonio cultural de Galicia, na categoría de Conxunto Histórico.

\section{A Fonte de Troncoso}

A Fonte de Troncoso sitúase na ribeira do río Tea e figura no Catálogo de Bens Culturais do Concello de Mondariz-Balneario cun grao de protección integral e tamén no Plan Básico Autonómico aprobado pola Xunta de Galicia (clave 39005361), o que inicialmente a dota dun nivel de protección legal suficiente para asegurar a súa conservación. 
O Manacial de Troncoso no Saidoiro, xunto co da Gándara, cuxas propiedades salutíferas foron recoñecidas por Pedro Gómez de Bedoya en 1772 e eran ben coñecidas a mediados do século XIX (Reboreda 2019), deron lugar ao nacemento neste último século do Balneario de Mondariz. En 1858 o párroco Domingo Blanco Lage acondiciona o manancial, e en 1864 analízanse por primeira vez as augas. “As augas foron declaradas de utilidade pública en 1873” (Id.).

En 1907 a familia Peinador gaña un preito ao Concello de Mondariz pola titularidade da Fonte e nese momento constrúe un muro de contención para evitar as inundacións frecuentes, unha escalinata para baixar a tomar as augas e comeza unhas obras para realizar unha galería cuberta e almacéns para botellas, un proxecto que, xunto co da Fonte da Gándara, será obra de Antonio Palacios, amigo persoal de Enrique Peinador Lines, propietario do balneario, e que se desenvolve en 1909. Este proxecto non chegou a rematarse na súa totalidade, segundo Reboreda.

O edificio componse de dous volumes arquitectónicos: un bloque de planta rectangular, realizado en cantaría de granito, que nas fachadas $\mathrm{N}$ e S conta con tres ocos rectangulares rematados por arcos de medio punto semellantes aos que articulan os frontis dos edificios da Gándara e da Baranda, nunha intencionalidade por parte de Palacios, segundo comenta Reboreda, de homoxeneizar o estilo dos tres edificios na súa monumentalización, dotando dunha unidade formal todo o Balneario, como tamén se recoñece no anterior informe comentado. Este primeiro corpo está articulado en soto, onde se localiza o embotellamento de auga mineral, e planta baixa, dividida en cinco estancias (cociña, dous dormitorios, sala e despacho para o administrador).

O segundo corpo componse dunha marquesiña anexa ao anterior, de planta rectangular, realizada en fundición de ferro. Ten un soto, que alberga o manancial, e a planta localizada na rasante do paseo, dende a que se pode contemplar o río dende o balcón cuberto e voado. Para baixar ao manancial disponse unha dupla escalinata curva e cuberta, que xera unha sensación de movemento semellante á da Fonte da Gándara.

\section{Problemática}

A Fonte viuse afectada nos últimos anos por unha serie de afeccións, consecuencia da falta de mantemento e conservación xeral do inmoble, que conduciron a un estado de deterioración cada vez maior que fai perigar a conservación do sitio. 
Por unha parte, o corpo de pedra do edificio contaba cunha cuberta de tella plana a catro augas que en maio de 2019 sufriu un derrubamento que tamén destruíu por completo o piso alto, polo que unicamente quedan en pé os muros de carga, sen protección; o que, coa incidencia da auga, pode provocar fendas e consecuentemente a súa desestabilización e posible derrubamento. Por outra, a marquesiña e as súas varandas modernistas atópanse en moi mal estado de conservación, o que fixo que se pechase o acceso ao público por motivos de seguridade.

Todo iso xera a desvinculación deste elemento co percorrido e paseo relacionados co Hotel-Balneario, a ruptura da unidade cultural arquitectónica e paisaxística, o impedimento do desfrute público e a falta de protección que permita a súa conservación.

\section{Conclusión}

Tendo en conta os valores da Fonte de Troncoso como elemento representativo da arquitectura relacionada coa auga realizada polo arquitecto Antonio Palacios en Mondariz-Balneario, o seu papel dentro da unidade do Conxunto do HotelBalneario de Mondariz - un elemento senlleiro da época no concello-, o seu grao de protección e o estado en que se atopa, solicitamos á Administración galega que aplique medidas de protección activas que garantan a conservación dos bens protexidos que formen parte do patrimonio cultural de Galicia xa que os titulares da Fonte de Troncoso non están levando a cabo a súa obriga na protección deste elemento.

Lembramos que, segundo o art. 32 do Estatuto de autonomía, correspóndelle ao goberno da Xunta a defensa e promoción dos valores culturais do pobo galego. Ademais a Lei 5/2016, do patrimonio cultural de Galicia, establece que o goberno da Xunta posúe a competencia exclusiva en materia de patrimonio histórico, artístico, arquitectónico e arqueolóxico. O mesmo texto legal fixa no seu art. 32 o deber de conservación: “As persoas propietarias, posuidoras ou arrendatarias e, en xeral, as titulares de dereitos reais sobre bens protexidos integrantes do patrimonio cultural de Galicia están obrigadas a conservalos, mantelos e custodialos debidamente e a evitar a súa perda, destrución ou deterioración”. Se non o fan, a Administración galega está obrigada a aplicar medidas de protección activas que garantan a súa conservación.

\section{Bibliografía}

Reboreda, A. (2019): “A Fonte de Troncoso. Historia do manancial do Saidoiro”. Faro da Cultura (Faro de Vigo, xoves, 23 de maio de 2019). 